\title{
PERANCANGAN MULTIMEDIA PEMBELAJARAN MATEMATIKA BERBASIS INQUIRI UNTUK SISWA KELAS IV SEKOLAH DASAR
}

\author{
Ade Sri Madona ${ }^{1 *}$, Ashabul Khairi ${ }^{2}$ \\ ${ }^{I}$ Pendidikan Guru Sekolah Dasar FKIP Universitas Bung Hatta, Padang \\ ${ }^{2}$ Program Studi Pendidikan Teknik Informatika dan Komputer FKIP Universitas Bung Hatta \\ *Email: adesrimadona@bunghatta.ac.id
}

\begin{abstract}
This study aims to produce a learning media design in the form of multimedia mathematics based inquiry learning for fourth grade students of elementary school. This type of research is development research using the 4D model. This study looks at how the procedures for developing multimedia learning mathematics learning are viewed from the form of flowcharts, Storyboarding, and multimedia programming results of mathematics learning. Then validation was seen from 3 aspects including the content aspect, constructive aspects and language aspects. From the results of the research that has been carried out obtained the average validation of 84.5 with a very valid category. Based on the research data that has been obtained, it can be concluded that the multimedia learning mathematics based inquiry has been valit and can be used in learning in elementary school.
\end{abstract}

Keywords: Multimedia Development, Mathematics, Inquiry.

\section{PENDAHULUAN}

Pembelajaran Matematika adalah proses belajar mengajar yang dibangun guru meningkatkan kreatifitas dan kemampuan berfikir siswa serta mengkontruksi pengetahuan baru sebagai upaya meningkatkan penguasaan materi matematika. Matematika merupakan ilmu universal yang mempunyai peran penting terhadap berbagai disiplin ilmu dan daya pikir manusia serta mendasari terhadap perkembangan teknologi modern. Bidang teori bilangan, aljabar, analisis, teori peluang dan matematika diskrit menjadi landasan terhadap perkembangan teknologi informasi dan komunikasi (BSNP, 2006).

Semua siswa mulai dari SD dipandang perlu mempelajari matematika dengan dibekali kemampuan berpikir kritis, logis, kreatif sistematis, analitis, juga kemampuan bekerjasama, agar peserta didik mampu memiliki kemampuan mengelola, memperoleh, dan berkomunikasi.
Pembelajaran Matematika mestinya ditampilkan semenarik mungkin agar siswa mudah memahami pembelajaran matematika. Akan tetapi bila dilihat kenyataannya di sekolah, proses pembelajaran mata pelajaran Matematika yang dilaksanakan oleh guru masih memiliki banyak keterbatasan diantaranya adalah (1) guru masih sering terfokus pada pembelajaran manual dari awal hingga berakhirnya pembelajaran matematika, seperti menerangkan rumus-rumus matematika tanpa ada bantuan media (2) tidak banyak media yang mendukung untuk pembelajaran matematika, selain itu, (3) Masih rendahnya tingkat pemahaman siswa dalam menyelesaikan atau memecahkan masalah pada pembelajaran matematika, (4) Hasil belajar matematika siswa rendah pada pembelajaran matematika dan sedikit sekali yang mencapai nilai KKM, (5) tidak adanya media yang interaktif seperti multimedia yang dipergunakan guru dalam 
mengajar sehingga pembelajaran menjadi monoton.

Dengan permasalahan yang dijumpai, hendaknya pembelajaran matematika harus disajikan semenarik mungkin dikarenakan pembelajaran matematika sangat berperan penting dalam menunjang kemampuan berpikir sistematis, logis, kritis, kreatif dan analitis, juga bekerjasama. Diantara tujuan pengajaran matematika di SD adalah: (1) Memahami konsep matematika, (2) Melakukan manipulasi matematika (3) Merancang model matematika, (4) Mengkomunikasikan gagasan dengan simbol, tabel, diagram (5) memiliki rasa ingin tahu, perhatian, dan minat dalam mempelajari matematika (BSNP, 2006).

Dari permasahan yang dijumpai dalam pembelajaran matematika, kondisi ideal yang ingin dicapai adalah perlu dikembangkannya suatu media pembelajaran agar dapat mengatasi permasalan yang dijumpai. Menurut (Kunandar, 2011) Media merupakan materi yang tertulis dan tersusun secara sistematis sehingga pembaca dapat memahami isi materi tersebut yang bertujuan sebagai bahan pelajaran siswa Media dapat meningkatkan kemampuan siswa dari satu unit pelajaran ke pelajaran lainnya yang dilakukan secara individual. Media yang dimaksud adalah Multimedia Pembelajaran Matematika Berbasis Inquiri untuk Siswa Kelas IV Sekolah Dasar dalam Rangka Mengimplementasikan Kurikulum 2013 (Ramansyah, 2014).

Menurut Munir, 2012 "Multimedia berasal dari kata multi dan media. Multi berasal dari bahasa latin, yaitu nouns yang berarti banyak atau macam-macam. Sedangkan kata media berasal dari bahasa latin, yaitu medium yang berarti perantara atau yang dipakai untuk menghantarkan, menyampaikan atau membawa sesuatu". Bahan ajar yang digunakan hendaknya dapat berinteraksi dangan siswa tanpa dibantu oleh guru (Madona, 2014).

\section{METODE PENELITIAN}

Jenis dan Model Penelitian

Penelitian yang dilakukan adalah penelitian pengembangan atau development research dengan menggunakan model 4-D. Prosedur rancangan pengembangan perangkat pembelajaran dapat dirincikan sebagai berikut:

\section{Tahap Pendefenisian (define)}

Tahap ini dilakukan untuk mendefenisikan dan menetapkan syarat-syarat pembelajaran. langkah-langkah kegiatan dalam tahap ini antara lain: analisis kurikulum, analisis kebutuhan, analisis peserta didik.

\section{Tahap Perancangan (design)}

Tahap perancangan adalah merancang perangkat bembelajaran multimedia berdasarkan flowchart, Storyboard dan pemrograman.

\section{Tahap Pengembangan (develop)}

Pada penelitian ini tahap develop digunakan untuk mengukur kevalidan produk oleh pakar yakni d e ng a n melakukan validasi perangkat pembelajaran sebelum diberikan kepada pengguna.

Intrumen Penelitian

Adapun instrumen penelitian yang dikembangkan untuk mengumpulkan data dalam penelitian ini menggunakan Lembar validasi Multimedia interaktif oleh Pakar. mendefinisikan Lembar validasi sebagai sebuah daftar pertanyaan yang harus diisi oleh pakar yang nantinya akan dievaluasi. validasi yang dilakukan dilihat dari 3 aspek diantaranya aspek konten, aspek konstruk dan aspek bahasa.

Teknik Analisis Data

Tabel 1. Kategori Kevalidan Multimedia Interaktif

\begin{tabular}{ccc}
\hline No & Tingkat Pencapaian $(\%)$ & Kategori \\
\hline 1 & $81-100$ & Sangat Valid \\
2 & $61-80$ & Valid \\
3 & $41-60$ & Cukup Valid \\
4 & $21-40$ & Kurang Valid \\
5 & $0-20$ & Tidak Valid \\
\hline
\end{tabular}

Sumber: (Riduan, 2009) 
Hasil validasi kemudian dianalisis. Teknik analisis data yang digunakan adalah data kualitatif dalam bentuk deskriptif yang mendeskripsikan validitas, media pembelajaran. Hasil validasi menggunakan skala Likert yang disajikan dalam tabel. Mencari rata-rata dengan rumus:

$$
\mathrm{R}=\frac{\sum_{\mathrm{j}=1}^{\mathrm{n}} \mathrm{Vij}}{\mathrm{nm}}
$$

(Muliyardi, 2006)

Keterangan:

$\mathrm{R}=$ Rata-rata hasil penilaian dari para ahli atau praktiksi

Vij = Hasil Skor penilaian para Ahli/praktisi

$\mathrm{n} \quad=$ Jumlah ahli atau praktisi yang menilai

$\mathrm{m}=$ Jumlah kriteria

Dengan kategori nilai pencapaian validasi digunakan klasifikasi menurut Ridwan dalam Tabel 1.

\section{HASIL DAN PEMBAHASAN}

Dalam pelaksanaan penelitian dilaksanakan 3 tahap yaitu: Tahap Pendefenisian (define), Tahap Perancangan (design) dan Tahap Tahap Pengembangan (develop). Analisis yang dilakukan pada tahap pendefenisisan terdiri dari analisis kurikulum, analisis kebutuhan, analisis peserta didik.

Analisis Kurikulum dilakukan dengan menyesuaikan media yang akan dibuat dengan materi yang ada pada kurikulum. Kurikulum yang dipakai adalah kurikulum K13 kelas IV SD. Analisis kebutuhan yang diperoleh melalui pengamatan di Kelas IV Semester 1 SDN 06 Simpang Haru Padang adalah masih terbatas dan tidak tersedianya media pembelajaran berbasis TIK, hal ini mengakibatkan pembelajaran menjadi monoton dan siswa sulit untuk memahami pembelajaran yang dilakukan. Disamping itu, guru juga mengalami kesulitan untuk menggunakan dan penyajian materi dalam bentuk TIK, jikapun ada, guru hanya menggunakan media pembelajaran dalam bentuk power point saja.

Tahap Perancangan (design)

Pada tahap perancangan dilakukan perancangan perangkat pembelajaran multimedia berdasarkan flowchart, Storyboard dan pmograman yang dilakukan.

Membuat Flowchat

Adapun bentuk flowchart yang digunakan dimodifikasi dari Susilana \& Riyana, 2007 antara lain sebagai berikut (lihat Gambar 1).

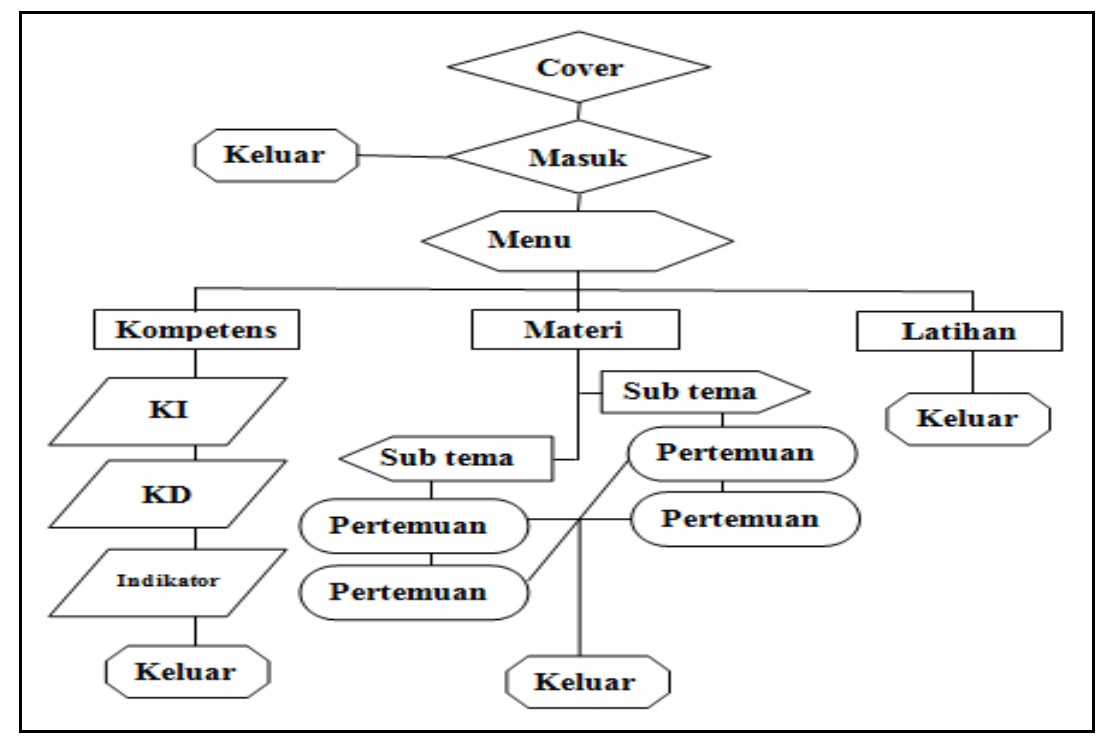

Gambar 1. Flowchart Sistem 
Madona, AS., Khairi, A. 2018. Perancangan Multimedia Pembelajaran Matematika Berbasis Inquiri untuk Siswa Kelas IV Sekolah Dasar. Sainstek : Jurnal Sains dan Teknologi. 10 (2) : 56-62

\subsubsection{Membuat Storyboard,}

Pada tahap ini yaitu melakukan visualisasi teks yang mendeskripsikan scene. Semua objek dicantumkan dan menglinkkan ke scene lainnya. atau menggambarkan bentuk aplikasi yang akan dibuat. Storyboard merupakan gambaran suatu cerita yang terbentuk melalui susunan rangkaian gambar manual. Storyboard menggambarkan tampilan dari setiap scene. Langkah pertama membuat scene awal yg merupakan tampilan pertama yang dilihat user, setelah itu Storyboard dalam scene berikutnya, yaitu halaman tempat input yang akan disampaikan dalam program ini. Storyboard dikembangkan untuk setiap topik (lihat Gambar 2 dan 3).

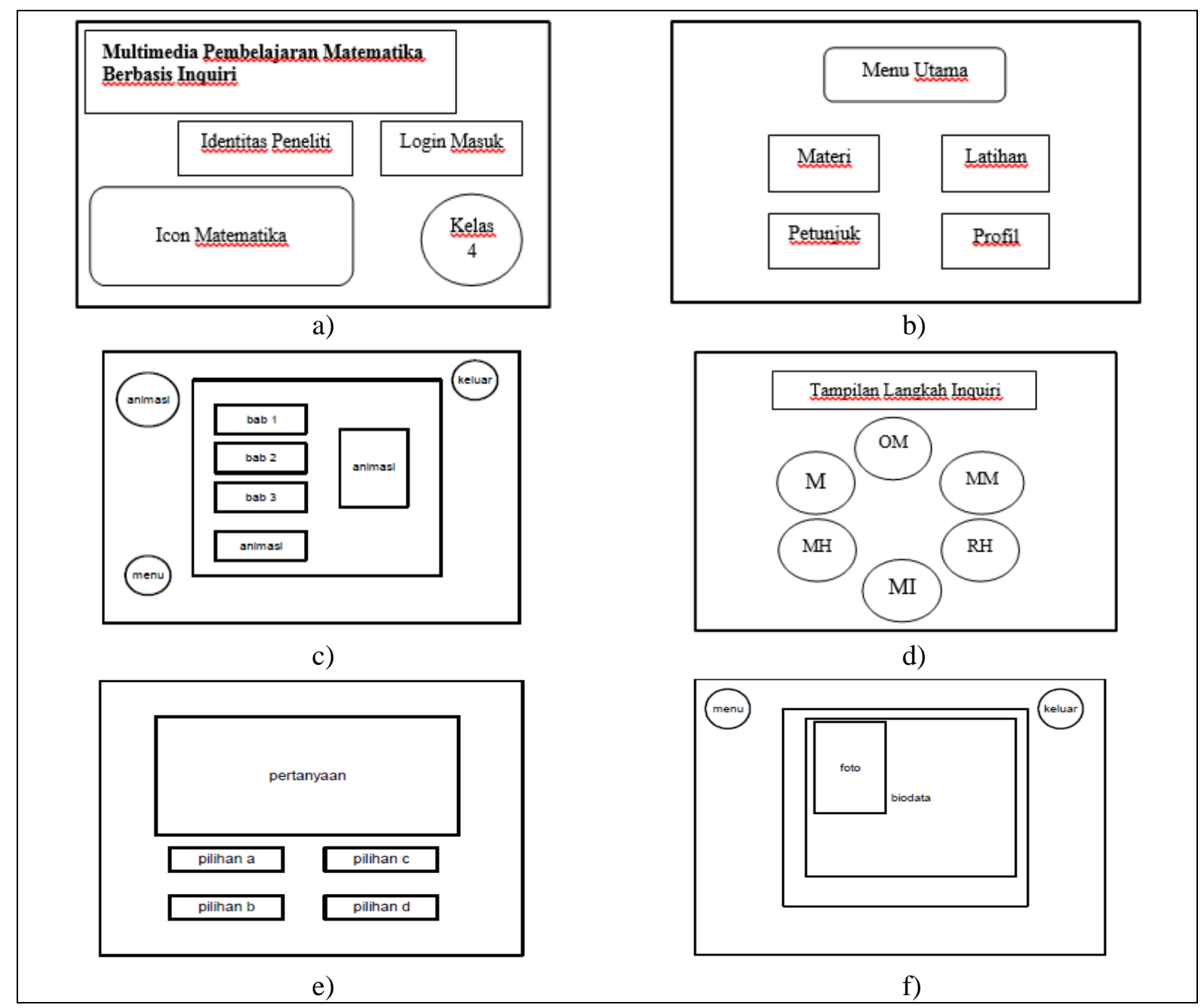

Gambar 2. Story board a) Tampilan cover, b) Tampilan Menu Utama, c) Tampilan Menu isi Materi, d) Tampilan Langkah Inquiri pada Materi, e) Tampilan Latihan, f) Tampilan Profil. 
Madona, AS., Khairi, A. 2018. Perancangan Multimedia Pembelajaran Matematika Berbasis Inquiri untuk Siswa Kelas IV Sekolah Dasar. Sainstek : Jurnal Sains dan Teknologi. 10 (2) : 56-62

\subsubsection{Hasil Implementasi (Pemrograman)}

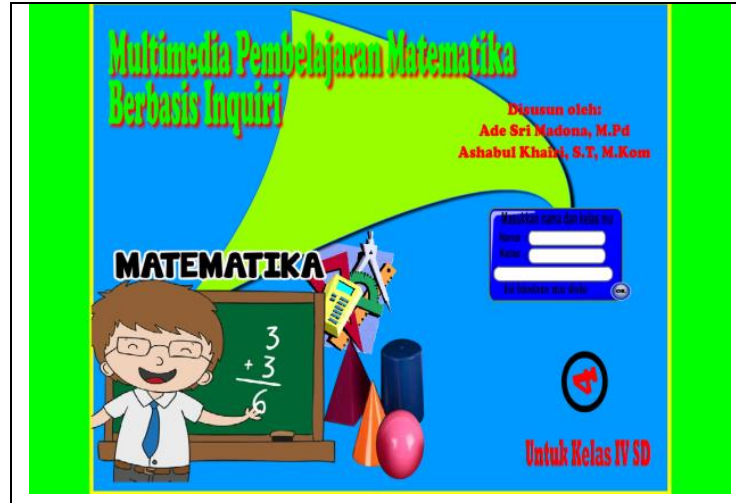

a)

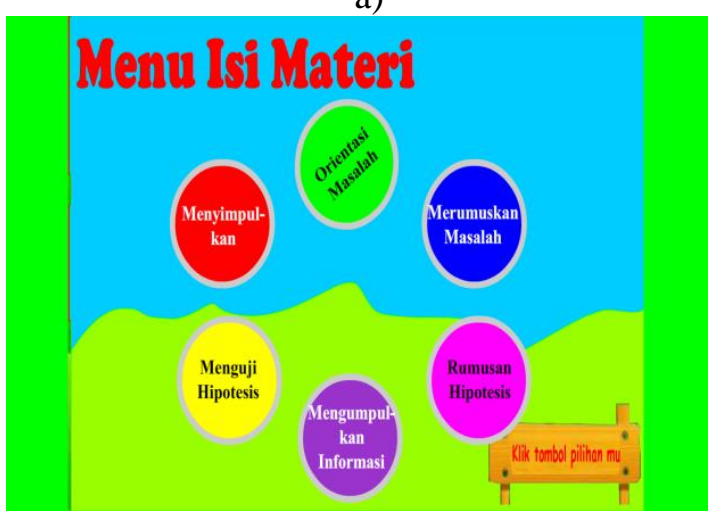

c)

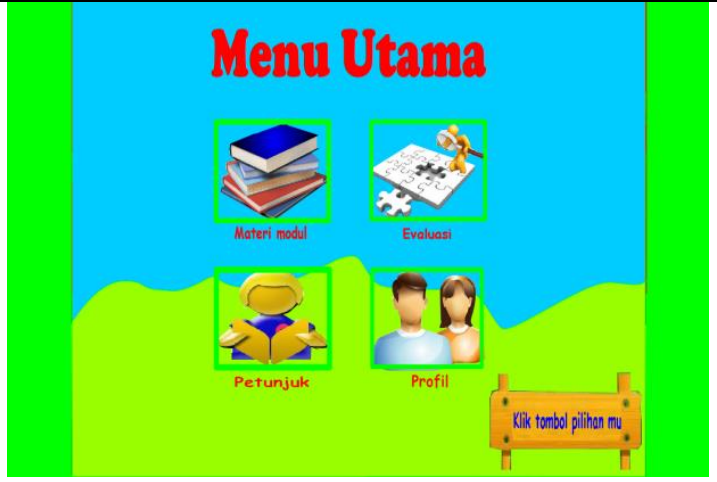

b)

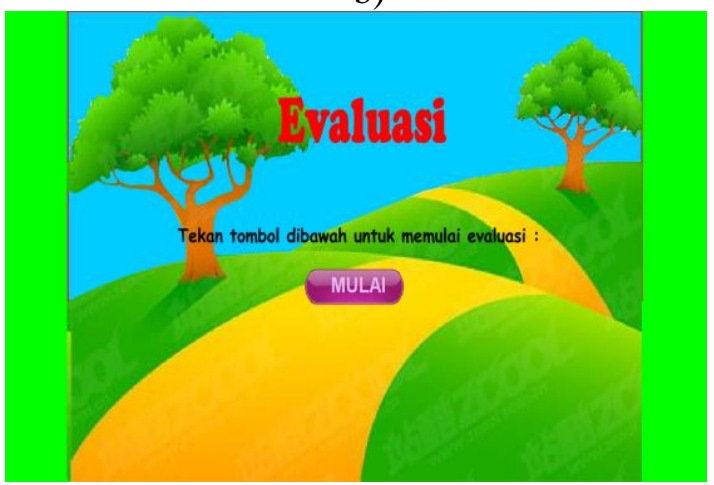

d)

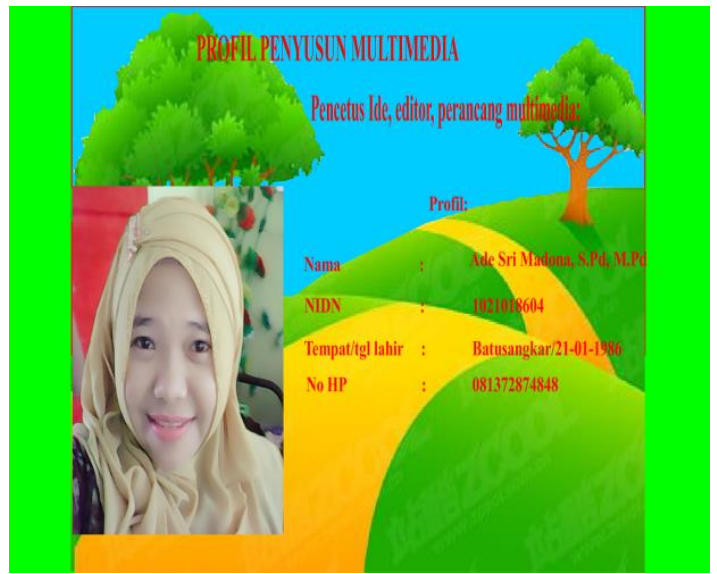

e)

Gambar 3. Hasil Implementasi Pemograman, a) Tampilan Cover, b) Tampilan Menu Utama, c) Tampilan Menu Isi Materi, d) Tampilan Evaluasi, e) Tampilan Profil 
Tabel 2. Hasil Validasi Multimedia

\begin{tabular}{|c|c|c|c|}
\hline No & Aspek & Rata-rata & Kategori \\
\hline 1 & Konstruk & 84,6 & Sangat Valid \\
\hline 2 & Konten & 86,5 & Sangat Valid \\
\hline 3 & Bahasa & 82,4 & Sangat Valid \\
\hline \multicolumn{2}{|c|}{ Rata-rata } & 84,5 & Sangat Valid \\
\hline
\end{tabular}

Tahap Pengembangan (develop)

Pada tahap ini dilakukan uji kevalidan oleh 3 orang pakar. validasi yang dilakukan dilihat dari 3 aspek diantaranya aspek konten, aspek konstruk dan aspek bahasa.

Multimedia interaktif direvisi sesuai dengan hasil diskusi dan saran-saran dari validator.

Validitas diperlukan dalam menguji suatu penelitian. Kata validitas adalah kebenaran, keshahihan, ketepatan atau keabsahan (Sugiyono, 2011). (Plomp, 2010) berpendapat produk yang dikatakan valid apabila produk tersebut berkarakteristik bisa merefleksikan jiwa pengetahuan (state of the art knowledge). Produk dikatakan valid jika telah memenuli kriteria tertentu.

Secara keseluruhan validitas dari multimedia Matematika berbasis inquiri dapat dilihat pada Tabel 2. Dapat diketahui bahwa mulltimedia dikategorikan sangan valid dengan Rerata 84,5. Sehingga produk layak untuk diujicoba pada tahap selanjutnya.

Data penelitian menunjukkan pnilaian dari pakar terhadap media dikategorikan sangat valid. Hal ini menunjukkan multimedia dapat dipergunakan sebagai sarana pembelajaran. Dilihat dari beberapa aspek penilaian yaitu aspek konstruk, konten dan bahasa. Penilaian media oleh pakar bisa dijadikan tolak ukur untuk mengetahui layak atau tidaknya multimedia interaktif dipergunakan di sekolah dasar khususnya pada kelas IV SD. Hal tersebut bisa menjadikan acuan agar siswa senang belajar dan pada akhirnya dapat mengatasi permasalahan yang dijumpai pada pembelajaran.

\section{KESIMPULAN}

Media pembelajraan matematika berbasis inquiri untuk siswa Kelas IV Sekolah Dasar berada pada kategori sangat valid. Validasi perangkat multimedia pada aspek konstruk, konten, dan Bahasa berada pada kategori sangat valid dengan Rata-rata keseluruhan 84,5.

Karena menyadari bahwa penelitian ini hanya terbatas pada validasi saja, maka tahap uji coba dan penyebaran dilaksanakan pada semester berikutnya.

\section{UCAPAN TERIMA KASIH}

Penulis mengucapkan terimakasih Kepada Donatur Penelitian yaitu Dirjen Dikti dan Rektor Universitas Bung Hatta serta LPPM

\section{DAFTAR KEPUSTAKAAN}

BSNP. (2006). Kurikulum Tingkat Satuan Pendidikan (KTSP). Jakarta: Departemen Pendidikan Nasional.

Kunandar. (2011). Langkah Mudah Penelitian Tindakan Kelas Sebagai Pengembangan Profesi Guru. Jakarta: Raja Grafindo Persada.

Madona, A. S. (2014). Peningkatan Aktivitas Belajar Siswa Kelas III dalam Pembelajaran Tematik Melalui Modul IPS berbasis multimedia interaktif Di SDN 12 Ulak Karang Utara Padang. Jurnal Cerdas Proklamator, 2(2), 205-202.

Muliyardi. (2006). Pengembangan Model Pembelajaran Matematika Menggunakan Komik di Kelas I Sekolah Dasar. In Disertasi tidak diterbitkan. Surabaya: 
Universitas Negeri Surabaya.

Munir. (2012). Multimedia, Konsep \& Aplikasi dalam Pendidikan. Bandung: Alfabeta.

Plomp, T. (2010). An Introduction to Educational Design Research. Netherlands: SLO Netherlands Institute for Curriculum Development.

Ramansyah, W. (2014). Pengembangan Multimedia Pembelajaran Interaktif Berbasis Adobe Flash CS3 pada Kelas 1 SDN Bancaran 3 Bangkalan. Jurnal
Ilmiah Edutic, 1(1), 4-13.

Riduan. (2009). Belajar Mudah Penelitian untuk Guru, Karyawan dan Peneliti Pemula. Bandung: Alfabeta.

Sugiyono. (2011). Metode Penelitian Kuantitatif Kualitatif dan $R \& D$. Bandung: Alfabeta.

Susilana, R., \& Riyana, C. (2007). Media Pembelajaran Hakikat, Pengembangan, Pemanfaatan dan Penilaian. Bandung: CV Wacana Prima. 